\title{
Food insecurity among Iraqi refugees living in Lebanon, 10 years after the invasion of Iraq: data from a household survey
}

\author{
Hala Ghattas ${ }^{1 *} \dagger$, AnnieBelle J. Sassine ${ }^{1} \dagger$, Karin Seyfert ${ }^{2}$, Mark Nord ${ }^{3}$ and Nadine R. Sahyoun ${ }^{4}$ \\ ${ }^{1}$ Department of Nutrition and Food Sciences, Faculty of Agricultural and Food Sciences, American University of Beirut, \\ PO Box 11-0236/NFSC, Riad El-Solh, Beirut 1107 2020, Lebanon \\ ${ }^{2}$ Department of Economics, School of Oriental and African Studies, Thornhaugh Street, Russell Square, \\ London WC1H OXG, UK \\ ${ }^{3}$ Economic Research Service, United States Department of Agriculture, 355 E Street SW, Washington, DC 20024-3221, USA \\ ${ }^{4}$ Department of Nutrition and Food Science, University of Maryland, 7965 Baltimore Avenue, College Park, MD 20740, USA \\ (Submitted 3 July 2013 - Final revision received 17 January 2014 - Accepted 20 January 2014 - First published online 17 April 2014)
}

\begin{abstract}
Iraqi refugees in Lebanon are vulnerable to food insecurity because of their limited rights and fragile livelihoods. The objective of the present study was to assess household food insecurity among Iraqi refugees living in Lebanon, almost 10 years after the invasion of Iraq. A representative survey of 800 UN High Commissioner for Refugees-registered refugee households in Lebanon was conducted using multi-stage cluster random sampling. We measured food insecurity using a modified US Department of Agriculture household food security module. We collected data on household demographic, socio-economic, health, housing and dietary diversity status and analysed these factors by food security status. Hb level was measured in a subset of children below 5 years of age ( $n$ 85). Weighted data were used in univariate and multivariate analyses. Among the Iraqi refugee households surveyed ( $n 630), 20 \cdot 1 \%(95 \%$ CI $17 \cdot 3$, 23.2) were found to be food secure, $35 \cdot 5 \%(95 \%$ CI 32.0, 39.2) moderately food insecure and 44.4\% (95\% CI 40.8, 48.1) severely food insecure. Severe food insecurity was associated with the respondent's good self-reported health (OR 0.3, $95 \%$ CI 0.2, 0.5), length of stay as a refugee (OR $1 \cdot 1$, $95 \%$ CI $1 \cdot 0,1 \cdot 2)$, very poor housing quality (OR $3 \cdot 3,95 \%$ CI $1 \cdot 6,6 \cdot 5)$ and the number of children in the household (OR $1 \cdot 2,95 \%$ CI $1 \cdot 0$, $1 \cdot 4)$, and resulted in poor dietary diversity $(P<0.0001)$. Anaemia was found in $41 \%(95 \%$ CI 30.6, 51.9) of children below 5 years of age, but was not associated with food insecurity. High food insecurity, low diet quality and high prevalence of anaemia in Iraqi refugees living in Lebanon call for urgent programmes to address the food and health situation of this population with restricted rights.
\end{abstract}

Key words: Refugees: Household food insecurity: Iraqi children

The Middle East has the highest regional concentration of refugees worldwide ${ }^{(1)}$. The displacement of Iraqis dates back to the Persian Gulf War (1990-1), and their numbers increased dramatically following the 2003 invasion of Iraq, during which approximately 2 million Iraqis fled to Syria, Jordan and Lebanon ${ }^{(2)}$. In 2011, the Office of the UN High Commissioner for Refugees (UNHCR) estimated that 8558 Iraqi refugees were living in Lebanon ${ }^{(3)}$. While some Iraqi refugees have been living in Lebanon for 10 years, some are recent refugees with lengths of stay of as little as 1 month. Unlike Palestinian refugees, Iraqis do not live in camps, but are rather dispersed within neighbourhoods, living alongside Lebanese communities.

Lebanon is not a state party to the 1951 Refugee Convention $^{(4)}$; therefore; refugees often remain in Lebanon illegally. Only the special ministerial decrees or Memoranda of Understanding negotiated $a d$ boc by the UNHCR reduce an otherwise constant risk of deportation. Thus, refugees' rights in Lebanon are severely curtailed. Iraqi refugees face rising rent, food and utility costs, further aggravated by the current crisis in Syria and an enormous influx of Syrian refugees. It is virtually impossible for Iraqi refugees, unlike Syrian refugees, to find legal, gainful employment. Although the UNHCR provides or subsidises health care, education and some financial assistance, meeting basic needs including adequate food, health care and education remains a challenge for many ${ }^{(4)}$.

Food security, defined as sustainable physical and economic access by all people at all times to sufficient, safe and nutritious food to meet their dietary needs and food

Abbreviations: HDDS, household dietary diversity score; UNHCR, UN High Commissioner for Refugees.

*Corresponding author: Assistant Professor H. Ghattas, fax +961 1744 460, email hg15@aub.edu.lb

† Both authors contributed equally to this work. 
preferences for a healthy and productive life ${ }^{(5)}$, among Iraqi refugees is likely to be compromised. In fact, two surveys conducted in Jordan and Syria in 2008 and 2009, respectively, have found food insecurity to be a major concern among Iraqi refugees and shown a need for improved food and cash assistance to this vulnerable population ${ }^{(6)}$.

Household food insecurity has been proposed as one of the main underlying factors for poor nutritional status, particularly in children ${ }^{(7)}$. Food insecurity is associated with decreased dietary diversity and intake of essential micronutrients, leading to nutritional deficiencies as well as increased risk of diet-related chronic diseases ${ }^{(8)}$. Studies from lowincome countries have shown an association between the severity of household food insecurity and the risk of child stunting ${ }^{(9)}$ and underweight ${ }^{(9,10)}$. In data from the USA, household food insecurity has been shown to increase the risk of diabetes $^{(11)}$ and risk factors of CVD, specifically hypertension and hyperlipidaemia ${ }^{(12)}$

Malnutrition (under- and overnutrition) and chronic diseases have the potential to further erode human capital, reduce resilience to shocks and decrease productivity ${ }^{(13)}$. The objective of the present study was to assess food security status among Iraqi refugees living in Lebanon, including an analysis of its socio-economic and demographic predictors, and its implications for dietary diversity and food quality.

To date, no report of the food security status of the Iraqi refugee population in Lebanon has been published.

\section{Materials and methods}

\section{Survey design and participant recruitment}

As part of a study commissioned by the UNHCR to profile the living conditions of refugees, a cross-sectional survey was conducted in January-February 2012. The detailed methodology of this survey has been described elsewhere ${ }^{(14)}$. In brief, the sampling frame consisted of an up-to date (October 2011) anonymised database of all UNHCR-registered refugees, including information on residence at the neighbourhood level. The survey was restricted to four regions: Beirut and its suburbs, Kesrouan, Metn and Baabda in which the majority ( $80 \%)$ of refugees reside, interspersed in Lebanese neighbourhoods. We proceeded by area sampling, constructing an area list where each neighbourhood with a size greater than twenty-five households constituted a cluster, and very large neighbourhoods were divided into subclusters. The total number of clusters was twenty-five. We stratified by region, and cluster sampling was implemented in each stratum whereby the clusters were sampled without replacement with probability proportional to the population size. Households were then randomly selected using a set algorithm that involved the entering of every third building and the selection of a set apartment.

Upon entering a household, oral consent was sought and eligibility was established. If the household approached did not include a UNHCR-registered refugee, we proceeded to the next household. Following the selection of a first household, snowball sampling was used, which is a method consisting of asking the respondent to give the address of other eligible respondents in the same neighbourhood. As an attempt to reduce possible bias, each snowballing chain included a maximum of five households. Data collectors were trained to administer the questionnaire to the individual responsible for food preparation, usually a senior female member of the household; otherwise, another adult household member was interviewed as the proxy respondent. The response rate was $90 \%$, indicating a low probability of response bias; $57 \%$ of the proxy respondents were male and $57 \%$ were the head of the household. In households with children under 5 years of age, one child was randomly selected using an algorithm, for the measurement of anaemia.

Sample size was calculated to obtain estimators with a maximum margin of error of $10 \%, 95 \% \mathrm{CI}$ and accounting for an estimated design effect of 2 (including childhood anaemia). Based on an average household size of $2 \cdot 5$, we aimed for a sample size of 800 households.

Informed consent forms, questionnaires and pamphlets were translated into Modern Standard Arabic, and were piloted and adjusted accordingly. The present study was approved by the American University of Beirut Institutional Review Board.

At the time of sampling (October 2011), the Syrian crisis had not yet led to a substantial influx of refugees to Lebanon, and Iraqi refugees constituted $96.4 \%$ of the UNHCR-registered refugees. Due to the small sample size of non-Iraqi refugees, the present study excluded them from the analysis, as we would not be able to draw any solid conclusions on their food security status.

\section{Data collection}

Socio-economic, demographic and health characteristics. The questionnaire included a household roster with questions on the individual's age, family status, educational attainment, employment and self-reported illness. All health characteristics were self-reported conditions occurring within 6 months before the interview. Family status was defined as singleperson household when a respondent reported not sharing food and budget with other individuals. Occupation was categorised according to the level of skill: non-highly skilled professions referred to clerks, service workers, agricultural and fishery workers, craft and trade workers, plant and machine operators, elementary occupations and armed forces.

Data on household characteristics such as household income, expenditure, assets, housing quality and assistance received were also collected. A food-related asset scale was derived based on the ownership of a refrigerator, freezer, oven and microwave, each contributing 1 point to the scale. Food assistance included food coupons, food baskets or fortified infant cereal. For housing quality, respondents rated the quality of their accommodation with respect to noise, dust, pollution, ventilation, exposure to sunlight and dampness, along a five-point scale with 1 being 'totally affected' and 5 being 'never affected'. Very poor quality housing was defined as having a household quality score less than 11 out of $30^{(15)}$ Household crowding referred to the number of individuals 
per room in the house (excluding kitchen, bathroom, garage and unclosed balcony).

Poverty was based on total household expenditure per adult equivalent, and poor households were defined as households that spend less than $\$ 6 \cdot 6 /$ person per $\mathrm{d}^{(14)}$.

Proxy respondents were asked about their own general health (self-reported health) including a question on selfreported feelings of happiness and depression, worded as 'In the past 4 months, how much of the time did you feel depressed and there was no way to be happy'. If the answer was never, then there was no indication of poor mental health, and if the answer was any of 'all of the time', 'most of the time' or 'some of the time', then there was an indication of poor mental health.

Household food security, dietary diversity and anaemia. Food security was assessed using a Household Food Security Questionnaire of seven questions derived from the eighteenitem US Department of Agriculture food security survey module $^{(16,17)}$ and the Yemeni Food Security Questionnaire ${ }^{(18)}$, and modified to the context of Iraqi refugees living in Lebanon. Questions were translated into Arabic, pilot tested and modified accordingly. The internal validity of the food security scale was verified using statistical methods based on the Rasch measurement model. Each positive response to any of the seven questions (Table 1) was counted as 1 point in the score. Households were categorised as follows: scores $0-2$, food secure; scores 3-5, moderately food insecure; scores 6 and 7, severely food insecure (NR Sahyoun, M Nord, AJ Sassine, K Seyfert, N Hwalla and H Ghattas unpublished results). Questions on coping mechanisms were adapted from the Coping Strategies Index ${ }^{(19)}$.

A twelve-item household dietary diversity score (HDDS) was used ${ }^{(20,21)}$. The list was populated with culturally specific food examples. Since data on an ideal HDDS are not available, tertiles of dietary diversity were calculated and the mean HDDS of the upper tertile was used as the reference ${ }^{(21)}$. A household food-frequency module using the same items as for the HDDS asked about the frequency of consumption of food groups by household members. We measured $\mathrm{Hb}$ levels in a subsample of children below 5 years of age using a finger-prick sample on a portable HemoCue device ( $\mathrm{Hb}$ 201; HemoCue AB). Calibration was checked before data collection, and quality controls were run on machines daily. Anaemia was defined as a $\mathrm{Hb}$ level below $110 \mathrm{~g} / \mathrm{l}^{(22)}$.

\section{Statistical analyses}

Data were analysed using Stata/se 11.1 (StataCorp). The data were set as survey data using the Stata svyset command, taking into account stratification, clustering and weights. Observations were weighted to account for varying selection probabilities and response rates (entire cases and items missing were deleted and considered as non-response).

Results are presented as observed weighted prevalence estimates and means. Adjusted Wald and $F$ tests were used to test for significance in differences between groups. Logistic regression was used to identify variables associated with food insecurity. In the multivariate model, predictors of food insecurity were selected by stepwise logistic regression analysis. Predictors were excluded if they did not improve the model fit or were collinear with other predictors. In case of collinearity, the predictor hypothesised to be more immediately associated with food insecurity was selected. Food consumption data were normalised using a log transformation in the form $\ln (x+1)$ to account for null values, and then back-transformed into the original scale using exponential transformation for the adjusted mean consumption of food groups.

Table 1. Derivation of the seven-point household food insecurity scale

\begin{tabular}{|c|c|c|}
\hline Food security questions & Response & Points \\
\hline \multirow{2}{*}{$\begin{array}{l}\text { 1. In the last } 6 \text { months, did you or any other member } \\
\text { in your household not eat for a whole day or go to } \\
\text { bed hungry because there was not enough food? }\end{array}$} & No & 0 \\
\hline & Yes $^{*}$ & 1 \\
\hline \multirow{2}{*}{$\begin{array}{l}\text { 2. In the last } 6 \text { months, did you or any other member } \\
\text { in your household ever cut the size of your meal } \\
\text { because there was not enough food? }\end{array}$} & No & 0 \\
\hline & Yes $^{*}$ & 1 \\
\hline \multirow{2}{*}{$\begin{array}{l}\text { 3. In the last } 6 \text { months, did you or any other member } \\
\text { in your household ever skip a meal because there } \\
\text { was not enough food? }\end{array}$} & No & 0 \\
\hline & Yes $^{*}$ & 1 \\
\hline \multirow{2}{*}{$\begin{array}{l}\text { 4. In the last } 6 \text { months, was there a time when you } \\
\text { were concerned that you would run out of food } \\
\text { for your household for the next month? }\end{array}$} & No & 0 \\
\hline & Yes $^{*}$ & 1 \\
\hline \multirow{2}{*}{$\begin{array}{l}\text { 5. Did the following statement apply to your household } \\
\text { in the last } 6 \text { months? 'The food that we bought } \\
\text { just didn't last and we didn't have money to get more.' }\end{array}$} & No & 0 \\
\hline & Yes $^{*}$ & 1 \\
\hline \multirow{2}{*}{$\begin{array}{l}\text { 6. Are there any foods you feel your family } \\
\text { does not eat enough of? }\end{array}$} & No & 0 \\
\hline & Yes* $^{*}$ & 1 \\
\hline \multirow{4}{*}{$\begin{array}{l}\text { 7. Which of these sentences applies the most to the food } \\
\text { eaten by your household during the past } 6 \text { months? } \\
\text { (select one answer only) }\end{array}$} & $\begin{array}{l}\text { We had enough to eat of the kinds of } \\
\text { food we wanted (quality and quantity) }\end{array}$ & 0 \\
\hline & $\begin{array}{l}\text { We had enough to eat but not always the } \\
\text { kinds of food we wanted (only quantity) }\end{array}$ & 1 \\
\hline & Sometimes we did not have enough to eat (quantity) & 1 \\
\hline & Often we did not have enough to eat & 1 \\
\hline
\end{tabular}

*'Yes' corresponds to all affirmative answers such as 'yes, almost every month', 'yes, in some months but not every month' and 'yes, in only 1 or 2 months'. 


\section{Results}

Of the 800 households approached, 773 were eligible and 700 (90.6\%) consented to be interviewed and at least partially completed the questionnaire. Of the 700 households, 639 (91.3\%) were Iraqi. Data on household food security were available for $98.6 \%$ of Iraqi refugee households ( $n$ 630), and included individual data for 2321 household members, whose characteristics are displayed in Table 2.

Overall, $20 \cdot 1 \%(95 \%$ CI $17 \cdot 3,23 \cdot 2)$ of all the households were food secure, $35 \cdot 5 \%$ (95\% CI 32.0, 39.2) were moderately food insecure and $44.4 \%$ (95\% CI $40.8,48 \cdot 1)$ were severely food insecure.

The severely food-insecure households had a higher mean number of children than the food-secure households $(P<0.0001)$, and had poorer housing quality than the moderately food-insecure and food-secure households $(P<0.0001$; Table 3). The food-insecure households (both moderate and severe) had a higher average household size and household crowding index $(P<0.0001$ and $P=0.0081$, respectively). Single-person households comprised a higher proportion of the food-secure and severely food-insecure categories, whereas there were more families in the moderately foodinsecure category $(P<0 \cdot 0001)$. Households living outside Beirut were more likely to be food insecure than those living in Beirut $(P<0 \cdot 0001)$. Severely food-insecure households were living in Lebanon for a longer period than the food-secure and moderately food-insecure households ( $P=0.0288$; Fig. 1). Of the severely food-insecure households with children under 5 years of age, $61.2 \%$ had mothers who had completed less than 10 years of schooling, compared with $46.8 \%$ of the food-secure households and $24.7 \%$ of the moderately food-insecure households ( $P=0.0112$; Table 3 ).

Table 3 shows that the age of the head of the household was slightly lower in the food-secure households, whereas sex, education and employment status of the head of the household were not associated with food insecurity. However, of the employed heads of the household, there was a higher proportion of unskilled workers in the severely food-insecure than in the food-secure households $(P=0 \cdot 04)$. Poverty was not significantly associated with food insecurity, but the severely food-insecure households had a significantly lower mean

Table 2. Demographic characteristics of individuals from 630 Iraqi refugee households living in Lebanon

(Estimate percentages or mean values and $95 \%$ confidence intervals)

\begin{tabular}{lccc}
\hline Characteristics & $n^{*}$ & Distribution & $95 \% \mathrm{Cl}$ \\
\hline Sex & 2321 & & \\
$\quad$ Male & & $53 \cdot 9$ & $52 \cdot 2,55 \cdot 6$ \\
$\quad$ Female & & $46 \cdot 1$ & $44 \cdot 5,47 \cdot 8$ \\
Mean age (years) & 2306 & $27 \cdot 6$ & $26 \cdot 8,28 \cdot 3$ \\
Age range (years) & 2306 & & \\
$\quad<5$ & & $8 \cdot 4$ & $7.4,9 \cdot 6$ \\
$5-17$ & & 25 & 23,27 \\
$18-59$ & & $61 \cdot 2$ & $59 \cdot 2,63 \cdot 2$ \\
$>60$ & $5 \cdot 4$ & $4.5,6 \cdot 6$ \\
\hline
\end{tabular}

${ }^{*} n$ differs due to missing values.

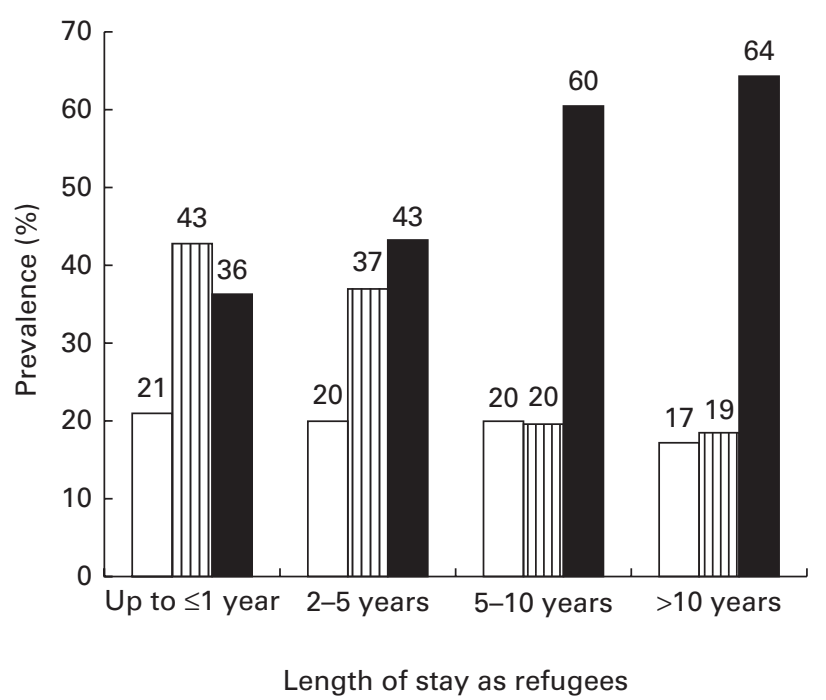

Fig. 1. Prevalence of household food insecurity by length of stay as refugees.

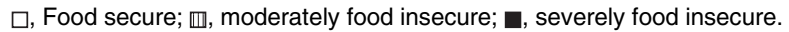

number of food-related assets $(P=0 \cdot 0062)$, spent less money on food per capita $(P=0 \cdot 0154)$ and were less likely to receive monthly remittances (OR $0.36,95 \%$ CI $0.13,0.6 ; P=0.001$ ) than the food-secure households.

Of the Iraqi refugee households, $65.8 \%$ received some kind of food assistance in the form of food coupons ( $57 \cdot 2 \%$, food baskets $(52 \%)$ or fortified infant cereals ( $4 \cdot 4 \%)$. However, the frequency of receiving food assistance was very low, with the majority (91\% for food coupons and 99\% for food baskets) only receiving assistance on occasions such as religious holidays or once per year. Most households (91\%) with children under the age of 2 years received food aid; $30 \%$ of these households received fortified infant cereal. Of the households who received fortified infant cereal, almost half received it monthly. The food-insecure households were more likely to receive any kind of food aid than the food-secure households $(P<0 \cdot 0001$; Table 3), with $87 \%$ of food aid going to the foodinsecure households.

The prevalence of diabetes among the adult refugees (>18 years of age) was $6.7 \%$, hypercholesterolaemia $2.5 \%$, hypertension $9.8 \%$ and chronic IHD $2 \%$. Table 4 shows that the severely food-insecure households were more likely to have at least one member who had a chronic disease $(51 \cdot 1 \mathrm{v}$. $31.4 \%$; OR $2 \cdot 3,95 \%$ CI $1.5,3.5 ; P<0.0001)$, hypertension (20.3 v. $12 \cdot 3 \%$; OR $1 \cdot 8,95 \% \mathrm{CI} 1 \cdot 0,3 \cdot 3 ; P=0 \cdot 05)$ or acute illness in the past 6 months than the food-secure households $(68 \cdot 3 v$. $43.2 \%$; OR $2 \cdot 8,95 \%$ CI $1.9,4 \cdot 3 ; P<0.001)$. Reports of chronic disease and hypertension were highest among the moderately food-insecure households. Proxy respondents in the severely food-insecure households were more likely to report poor health $(P<0.001)$ and feeling depressed $(P=0.0032)$ than those from the food-secure households (Table 3 ).

Multivariate logistic regression was used to investigate the predictors of severe household food insecurity (Table 4). Significant predictors of severe food insecurity were respondents with poor mental health, length of stay as refugees, very poor 
Table 3. Characteristics of Iraqi refugees living in Lebanon by levels of household $(\mathrm{HH})$ food security (Weighted percentages or mean values and $95 \%$ confidence intervals)

\begin{tabular}{|c|c|c|c|c|c|c|c|c|c|}
\hline & \multirow[b]{2}{*}{$n^{\star}$} & \multicolumn{2}{|c|}{ Food secure } & \multicolumn{2}{|c|}{$\begin{array}{l}\text { Moderately food } \\
\text { insecure }\end{array}$} & \multicolumn{2}{|c|}{$\begin{array}{l}\text { Severely food } \\
\text { insecure }\end{array}$} & \multicolumn{2}{|r|}{ Total } \\
\hline & & Mean & $95 \% \mathrm{Cl}$ & Mean & $95 \% \mathrm{Cl}$ & Mean & $95 \% \mathrm{Cl}$ & Mean & $95 \% \mathrm{Cl}$ \\
\hline \multicolumn{10}{|l|}{ HH demographics } \\
\hline $\mathrm{HH}$ size & 630 & $3 \cdot 2$ & $2 \cdot 8,3 \cdot 5$ & $4 \cdot 3$ & $4 \cdot 0,4 \cdot 5$ & $3 \cdot 8$ & $3 \cdot 5,4 \cdot 0$ & $3 \cdot 8$ & $3 \cdot 7,3 \cdot 9$ \\
\hline Number of children under 15 years of age & 630 & 0.7 & $0.5,0.8$ & $1 \cdot 1$ & $1 \cdot 0,1 \cdot 3$ & $1 \cdot 2$ & $1 \cdot 0,1 \cdot 3$ & 1.04 & $0.9,1 \cdot 1$ \\
\hline Geographic place of residence & 630 & & & & & & & & \\
\hline Beirut (\%) & & \multicolumn{2}{|r|}{$18 \cdot 3$} & \multicolumn{2}{|r|}{$5 \cdot 2$} & \multicolumn{2}{|r|}{6.5} & \multicolumn{2}{|r|}{$8 \cdot 4$} \\
\hline All other regions (\%) & & \multicolumn{2}{|r|}{$81 \cdot 8$} & \multicolumn{2}{|r|}{$94 \cdot 8$} & \multicolumn{2}{|r|}{$93 \cdot 6$} & \multicolumn{2}{|r|}{91.6} \\
\hline Living arrangement & 630 & & & & & & & & \\
\hline Single-person $\mathrm{HH}(\%)$ & & \multicolumn{2}{|r|}{$26 \cdot 3$} & \multicolumn{2}{|r|}{$6 \cdot 8$} & \multicolumn{2}{|r|}{$16 \cdot .3$} & \multicolumn{2}{|r|}{14.9} \\
\hline Families (\%) & & \multicolumn{2}{|r|}{$73 \cdot 8$} & \multicolumn{2}{|r|}{$93 \cdot 2$} & \multicolumn{2}{|r|}{83.7} & \multicolumn{2}{|r|}{$85 \cdot 1$} \\
\hline Length of stay as refugees (years) & 620 & $2 \cdot 7$ & $2 \cdot 2,3 \cdot 1$ & $2 \cdot 1$ & $1 \cdot 8,2 \cdot 4$ & $3 \cdot 4$ & $3 \cdot 0,3 \cdot 8$ & $2 \cdot 8$ & $2 \cdot 6,3 \cdot 0$ \\
\hline Maternal education $†$ & 91 & & & & & & & & \\
\hline Did not complete intermediate (\%) & & & $46 \cdot 8$ & & $24 \cdot 7$ & & $61 \cdot 2$ & & $46 \cdot 7$ \\
\hline $\mathrm{HH}$ crowding & 623 & $2 \cdot 0$ & $1 \cdot 8,2 \cdot 2$ & 2.5 & $2 \cdot 3,2 \cdot 7$ & $2 \cdot 3$ & $2 \cdot 2,2.5$ & $2 \cdot 3$ & $2 \cdot 2,2 \cdot 4$ \\
\hline Housing quality & 626 & & & & & & & & \\
\hline Very poor housing quality (\%) & & & $4 \cdot 1$ & & 4.6 & & $14 \cdot 8$ & & $9 \cdot 0$ \\
\hline Head of $\mathrm{HH}$ demographics & & & & & & & & & \\
\hline $\mathrm{HH}$ age (years) & 625 & $40 \cdot 2$ & $38 \cdot 2,42 \cdot 3$ & $44 \cdot 0$ & $42 \cdot 4,45 \cdot 7$ & $43 \cdot 3$ & $41 \cdot 8,44 \cdot 8$ & $42 \cdot 8$ & $41 \cdot 9,43 \cdot 8$ \\
\hline $\mathrm{HH}$ sex & 630 & & & & & & & & \\
\hline Female (\%) & & & $10 \cdot 4$ & & $12 \cdot 3$ & & $10 \cdot 9$ & & $11 \cdot 3$ \\
\hline $\mathrm{HH}$ education & 611 & & & & & & & & \\
\hline Did not complete intermediate (\%) & & & $40 \cdot 0$ & & $40 \cdot 6$ & & $43 \cdot .2$ & & $41 \cdot 7$ \\
\hline $\mathrm{HH}$ employment status & 604 & & & & & & & & \\
\hline Unemployed (\%) & & & $53 \cdot 1$ & & $51 \cdot 0$ & & $53 \cdot .9$ & & $52 \cdot 7$ \\
\hline $\mathrm{HH}$ type of occupation & 340 & & & & & & & & \\
\hline Non-highly skilled professions (\%) & & & 84.9 & & $88 \cdot 3$ & & $93 \cdot 6$ & & 90 \\
\hline $\mathrm{HH}$ socio-economic factors & & & & & & & & & \\
\hline Poverty status & 629 & & & & & & & & \\
\hline Poor HH (\%) & & & $20 \cdot 0$ & & $21 \cdot 0$ & & $23 \cdot 9$ & & $22 \cdot 1$ \\
\hline Receiving any kind of food assistance (\%) & & & $46 \cdot 4$ & & $77 \cdot 3$ & & 65.7 & & 65.9 \\
\hline Average monthly food expenditure per capita (USD) & 537 & 125 & 114,137 & 111 & 103,119 & 108 & 101,115 & 112 & 108,117 \\
\hline Average number of food-related assets & 628 & $2 \cdot 0$ & $1 \cdot 9,2 \cdot 1$ & $2 \cdot 0$ & $1 \cdot 9,2 \cdot 1$ & 1.8 & $1.8,1.9$ & 1.9 & $1 \cdot 87,2 \cdot 0$ \\
\hline $\mathrm{HH}$ health & & & & & & & & & \\
\hline At least one member reports chronic disease (\%) & 630 & & $31 \cdot 4$ & & $53 \cdot 3$ & & $51 \cdot 1$ & & $47 \cdot 9$ \\
\hline At least one member reports hypertension (\%) & 630 & & $12 \cdot 3$ & & $27 \cdot 3$ & & $20 \cdot 3$ & & $21 \cdot 2$ \\
\hline At least one member reports diabetes (\%) & 630 & & $8 \cdot 7$ & & $17 \cdot 3$ & & $13 \cdot 2$ & & $13 \cdot 7$ \\
\hline At least one member reports disability (\%) & 630 & & 9.8 & & $10 \cdot 2$ & & $11 \cdot 9$ & & $10 \cdot 9$ \\
\hline At least one member reports acute illness (\%) & 630 & & $43 \cdot 2$ & & $67 \cdot 3$ & & $68 \cdot 3$ & & 62.9 \\
\hline Respondent health & & & & & & & & & \\
\hline Respondent's self-reported health (\%) & 630 & & & & & & & & \\
\hline Very good/good & & & $49 \cdot 8$ & & $26 \cdot 4$ & & $22 \cdot 0$ & & $29 \cdot 2$ \\
\hline Fair & & & $37 \cdot 6$ & & $58 \cdot 8$ & & $50 \cdot 0$ & & $50 \cdot 6$ \\
\hline Not good/not good at all & & & $12 \cdot 5$ & & $14 \cdot 8$ & & $28 \cdot 0$ & & $20 \cdot 2$ \\
\hline Respondent's self-reported poor mental health (\%) & 630 & & $12 \cdot 6$ & & $12 \cdot 5$ & & $22 \cdot 5$ & & $17 \cdot 0$ \\
\hline
\end{tabular}

USD, US dollar.

${ }^{*} n$ corresponds to the number of observations, and it varies because of missing data.

† Maternal education only includes mothers of children below 5 years of age.

housing quality and number of children (under 15 years of age) in the household (Table 4).

Table 5 shows that the severely food-insecure households had a significantly lower mean HDDS than both moderately food-insecure and food-secure households $(P<0.0001$ and $P<0.0001$, respectively). This inverse association between food insecurity and the HDDS remained independently significant in a linear regression model correcting for all the predictors of severe food insecurity listed in Table 4 (coefficient - 0.62, SE 0.11; P<0.0001).

Also, moderate household food insecurity and severe household food insecurity were manifested by a significant reduction in the consumption of fruits $(P=0.04$ and $P<0.0001)$, meat
$(P=0.0354$ and $P<0.0001)$, fish $(P<0.0001$ and $P<0.0001)$, beverages $(P=0.0027$ and $P<0.0001)$ and sweets $(P=0.0015$ and $P<0.0001)$ in comparison with the food-secure households. The consumption of some food groups such as cereals $(P=0.002)$, pulses $(P=0.0027)$, dairy products $(P=0.0043)$ and fats $(P=0 \cdot 0005)$ was significantly reduced only when food insecurity was severe. Vegetable consumption was highest in the moderately food-insecure households (Table 5).

The most common coping strategies employed by foodinsecure Iraqi refugee households were borrowing money (21\%) and accepting a gift/donation (16\%).

Of the Iraqi children under 5 years of age, eighty-five had $\mathrm{Hb}$ measurement. The prevalence of anaemia was $41 \%$ 
Table 4. Logistic regression model ${ }^{\star}$ for predictors of severe food insecurity among Iraqi refugee households $(\mathrm{HH})$ in Lebanon (Odds ratios, mean values and $95 \%$ confidence intervals)

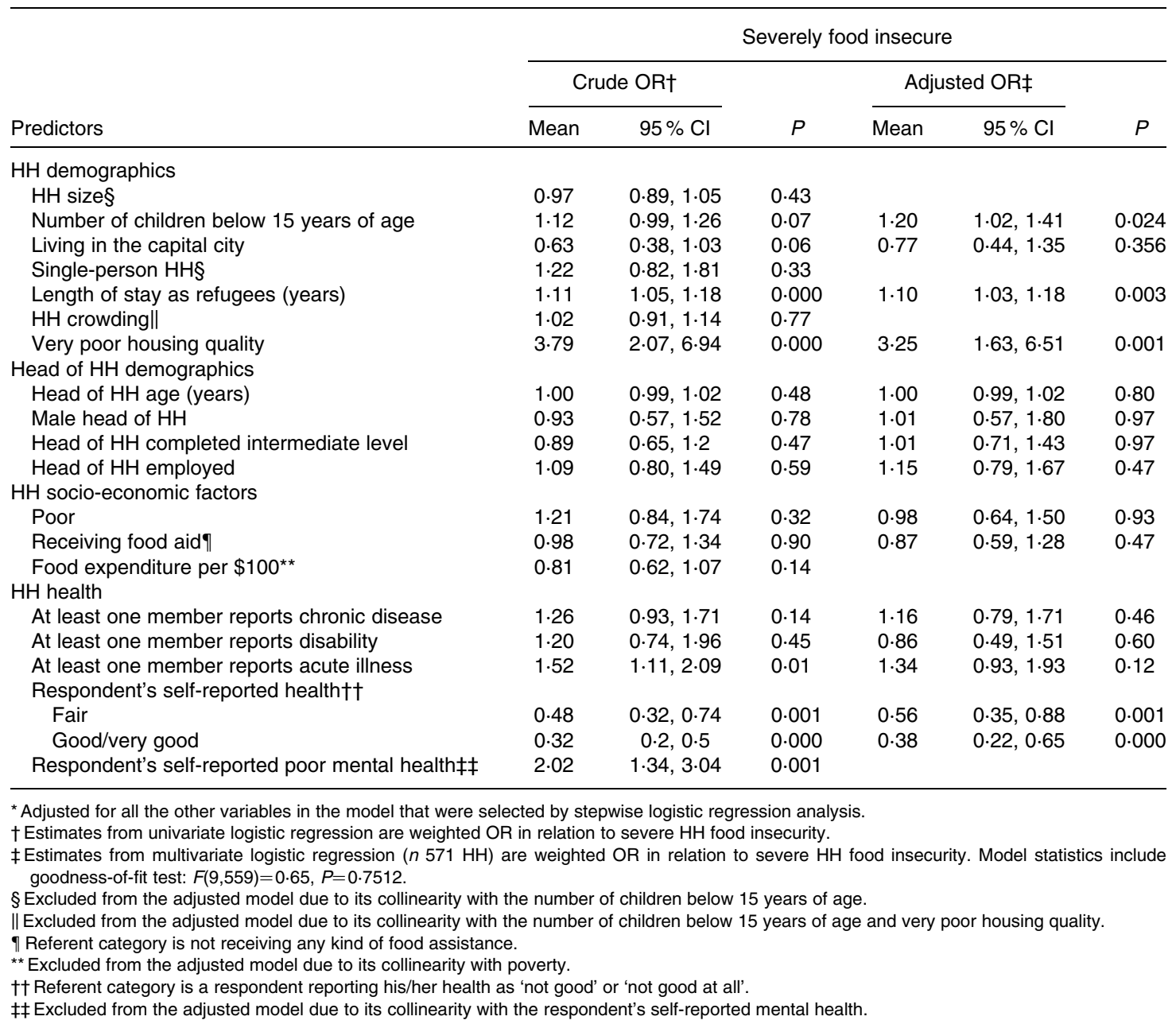

(95\% CI 30.6, 51.9). Anaemia was more common in children aged 6-24 months (59.3\%) compared with those above 2 years of age $(30 \cdot 8 \% ; P=0 \cdot 0146)$, but did not vary by household food security status or by the HDDS.

\section{Discussion}

The present study finds alarmingly high rates of food insecurity (80\%) among Iraqi refugees living in Lebanon, manifesting as poor dietary diversity; this is particularly the case in families with children, with poor housing conditions and that reported poor health. Iraqis are the second largest refugee population in the Middle East after Palestinians ${ }^{(23)}$. Although poverty rates among Iraqi refugees are significantly lower than those of Palestinian refugees living in Lebanon ${ }^{(24)}$, the present study shows that Iraqi refugees report universally higher rates of food insecurity; various factors may explain this observation.

One possibility is that Iraqi refugees are more recent refugees than Palestinians whose displacement began in 1948.
Palestinian refugees are therefore more likely than Iraqis to have built social networks over time that may have resulted in collective resources that protect against food insecurity.

Alternatively, the subjective measure of food insecurity used in the present study may be related to some extent with dissatisfaction, poor self-reported health and poor mental health - due to the relative deprivation of Iraqis in comparison with their pre-refugee situation. In fact, reported poor mental health is strongly associated with severe food insecurity, in line with other studies ${ }^{(25-29)}$. Although recent results from a prospective birth cohort $^{(30)}$ have shown that food insecurity is a strong independent predictor of poor mental health in children, in refugee settings, it is likely that the general dissatisfaction and stress associated with conflict and displacement may lead to uniform reports of poor health, poor mental health and food insecurity.

This general dissatisfaction may be related to current policies limiting the rights of refugees to work and generate income, which can exacerbate food insecurity ${ }^{(4)}$. Only refugees who are in highly skilled employment are able to avoid 
Table 5. Dietary diversity of Iraqi refugee households in Lebanon by levels of food security (Weighted mean values and $95 \%$ confidence intervals; $n$ 576)

\begin{tabular}{|c|c|c|c|c|c|c|}
\hline & \multicolumn{2}{|c|}{ Food secure } & \multicolumn{2}{|c|}{$\begin{array}{l}\text { Moderately food } \\
\text { insecure }\end{array}$} & \multicolumn{2}{|c|}{$\begin{array}{l}\text { Severely food } \\
\text { insecure }\end{array}$} \\
\hline & Mean & $95 \% \mathrm{Cl}$ & Mean & $95 \% \mathrm{Cl}$ & Mean & $95 \% \mathrm{Cl}$ \\
\hline HDDS§ & $6 \cdot 8$ & $6 \cdot 4,7 \cdot 2$ & 6.4 & $6 \cdot 2,6 \cdot 7$ & $5 \cdot 6^{*}$ & $5 \cdot 4,5 \cdot 9$ \\
\hline \multicolumn{7}{|c|}{ Frequency of consumption of various food groups (times/week)\| } \\
\hline Vegetables & 4.8 & $4 \cdot 3,5 \cdot 4$ & $6 \cdot 2^{*}$ & $5 \cdot 6,6.9$ & 4.7 & $4 \cdot 3,5 \cdot 2$ \\
\hline Fruits & $6 \cdot 0^{*}$ & $5 \cdot 2,6 \cdot 5$ & $5 \cdot 0$ & $4.5,5 \cdot 6$ & $3 \cdot 6^{\star}$ & $3 \cdot 3,4 \cdot 0$ \\
\hline Cereals & 14.5 & $13 \cdot 2,16 \cdot 0$ & 14.2 & $13,15 \cdot 4$ & $11 \cdot 9^{*}$ & $11 \cdot 2,12.9$ \\
\hline Meat & $2 \cdot 6^{\star}$ & $2 \cdot 3,3 \cdot 0$ & $2 . \overline{2}$ & $1.9,2.4$ & $1.5^{\star}$ & $1.3,1.6$ \\
\hline Fish & $0.7^{\star}$ & $0.6,0.9$ & 0.3 & $0.3,0.4$ & $0.25^{\star}$ & $0.2,0.3$ \\
\hline Pulses & $1.6 \dagger$ & $1.4,1.9$ & 1.4 & $1.3,1.6$ & $1 \cdot 2$ & $1 \cdot 1,1 \cdot 3$ \\
\hline Dairy products & 4.9 & $4 \cdot 3,5 \cdot 7$ & 4.5 & $4 \cdot 0,5 \cdot 0$ & $3 \cdot 8^{\star}$ & $3.4,4 \cdot 2$ \\
\hline Beverages & $2 \cdot 2^{*}$ & $1 \cdot 8,2 \cdot 6$ & 1.5 & $1 \cdot 3,1 \cdot 8$ & 1.3 & $1 \cdot 1,1 \cdot 4$ \\
\hline Sweets & $2 \cdot 0^{*}$ & $1 \cdot 6,2.5$ & 1.3 & $1.1,1.5$ & $1.0^{*}$ & $0.8,1 \cdot 2$ \\
\hline Eggs & $3 \cdot 2$ & $2 \cdot 8,3.7$ & $3 \cdot 9^{*}$ & $3 \cdot 5,4 \cdot 3$ & 3.0 & $2 \cdot 7,3 \cdot 3$ \\
\hline Fats & 9.0 & $7 \cdot 9,10 \cdot 1$ & 8.7 & $7 \cdot 9,9.6$ & $6 \cdot 7^{\star}$ & $6 \cdot 1,7 \cdot 3$ \\
\hline Roots & $2 \cdot 7 \ddagger$ & $2 \cdot 3,3 \cdot 1$ & 3.3 & $2 \cdot 9,3.6$ & 2.9 & $2 \cdot 6,3 \cdot 2$ \\
\hline
\end{tabular}

HDDS, household dietary diversity score.

* Mean value was significantly different from those of the other two categories of household $(P<0.05$; independent $t$ tests for conditional variables).

$\dagger$ Mean value was significantly different from that of severely food-insecure households.

$\ddagger$ Mean value was significantly different from that of moderately food-insecure households.

$\S$ Households with missing household dietary scores were excluded from the analysis.

\| Frequency of consumption is available for 619 households. Means of the frequency of consumption are back transformed after using the log transformation In $(x+1)$ to achieve normality, and independent $t$ tests were performed to test for differences between the transformed mean consumptions.

food insecurity (Table 3), which crosses socio-economic, educational and employment boundaries.

The lack of a correlation between poverty and food insecurity may also be due to the poverty measure that we used which is based on expenditure, consistent with the literature showing the absence of an association between single indicators of poverty and food insecurity ${ }^{(31)}$. This single moneymetric measure of poverty only captures one dimension of economic deprivation faced by impoverished households ${ }^{(32,33)}$. In fact, we found that other measures of material hardship including crowding index, housing quality and foodrelated assets were all strongly correlated with our measure of household food insecurity even after adjusting for confounders. We considered the food-related asset index to be another marker of food insecurity (rather than poverty), and therefore excluded it from the model of predictors of household food insecurity. In fact, Beverly ${ }^{(34)}$ argued that food insecurity/ insufficiency is itself an indicator of material hardship. The present results indicate that food-insecure and poorly housed households were not able to further reduce their expenditure, implying that savings made on food and housing cannot be compromised further. In these most vulnerable refugees, poor housing is a significant predictor of severe food insecurity and can be used as an indicator of poverty, and hence as a targeting mechanism for food assistance programmes.

In the present study, the moderately food-insecure category includes more families than the food-secure and severely food-insecure categories. This is also likely related to the dichotomy in the 'single-person households' group. These are predominantly male (93\%) individuals who are unattached to or not living with other family members and are more likely to be either food secure or severely food insecure than households made up of greater than two persons. This dichotomy may result from two different sets of circumstances: (1) larger households benefit from economies of scale and offer social capital that could be serving as a buffer against food insecurity; (2) the absence of children or elderly may reduce the burden of responsibility and make some of these individuals more food secure.

In fact, a strong predictor of both moderate and severe food insecurity is the number of children present in the household (Tables 3 and 4). Minors unable to be economically productive place a burden on such households, similar to studies reporting on migrant populations elsewhere ${ }^{(35,36)}$ implying that large families with young children would particularly benefit from social safety net programmes including food aid. In fact, the UNHCR provides assistance to Iraqi refugees through programmes implemented by non-governmental organisation partners. Chaaban et al. ${ }^{(14)}$ found that cash-support and rent-support programmes do not reach the neediest; this may differentially affect impoverished households, allowing some, but not all, to spend less money on food. However, health, education, counselling and legal aid were found to be well targeted, with households including children below 2 years of age more likely to receive health assistance ${ }^{(14)}$. Similarly, we show that food-insecure households and households with young children are more likely to receive food assistance, indicating that food assistance is well targeted but insufficient to lift Iraqi refugees out of food insecurity, probably due to the sporadic nature of receipt of food aid in this population.

In the absence of sustained high-coverage food assistance, and in line with other studies, food-insecure households mainly resort to 'informal borrowing arrangements' ${ }^{\text {(35,37) }}$ and receiving food/money from relatives or friends ${ }^{(36,38)}$. 
The majority of Iraqi refugees have been living in Lebanon for the past $2-5$ years. In contrast to countries with permanent asylum policies where food insecurity decreases with time, we find that Iraqi refugees who stay in Lebanon for long periods are at a higher risk of severe food insecurity, probably due to their precarious legal status that limits their ability to improve their socio-economic standing through work; therefore, over time, as savings become depleted, the risk of food insecurity increases. Monthly remittances appear to counteract the effects of length of stay, with food-secure households more likely to receive these than severely food-insecure households $(P=0 \cdot 001)$.

In addition, the major compromise that food-insecure households resort to is the reduction in food variety, which is in line with a recent multi-country analysis showing a correlation between dietary diversity and household energy availability and food access ${ }^{(39)}$. On average, the dietary diversity of Iraqi refugee households is relatively low $(6 \cdot 2 v$. a target of 8.9), translating into low fruit and meat consumption and a high reliance on cereals and fats, with implications for micronutrient and protein intakes. With increased severity of food insecurity, consumption of foods such as fruit, meat, fish and sweets is further reduced. This could be due to the fact that fruit and meat are relatively expensive, particularly when compared with cereals, vegetables and oils, and are therefore the first foods to be reduced when food insecurity is encountered. Higher consumption of vegetables in moderately food-insecure households may be an artifact of household composition (larger families) or a reflection of coping by selecting cheaper vegetable-based dishes instead of meatbased dishes. Recent studies ${ }^{(40,41)}$ have shown associations between low dietary diversity and chronic diseases as well as nutritional deficiencies.

Although a causal relationship cannot be inferred with confidence between food insecurity and reported health outcomes due to the cross-sectional nature of the study and the fact that health outcomes are self-reported, we find universally high rates of non-communicable diseases that are consistent with the reports of high rates of obesity and hypertension in Iraqis resettled in the $\mathrm{USA}^{(42)}$. Concurrently, although the subsample size was small and there was no association with HDDS, anaemia in children below 5 years of age was found to be elevated when compared with the host population ${ }^{(43)}$. Both burdens of chronic diseases and anaemia in Iraqi refugees are high and will increase if food insecurity is not addressed. These findings suggest that Iraqi refugees living in Lebanon may be facing a double burden of malnutrition, a phenomenon that has only recently been described in protracted refugees in Algeria $^{(44)}$. As our findings may be limited by the small sample size and the lack of dietary data for children, further investigations are warranted, including studies that should examine the aetiology of anaemia in this population as well as dietary habits contributing to non-communicable diseases.

Since poor dietary diversity was strongly correlated with the severity of food insecurity, programmes aiming to increase the diet quality of refugees and to target assistance towards healthier and more diverse food options would be important. Given the context, fruit and vegetable vouchers (commodity-based or value-based), which have been proven successful in other studies ${ }^{(45)}$, could improve the micronutrient content of the refugee's diets and provide healthy food choices. Nutrition education could be important to complement voucher distribution in order to ensure that these are spent towards high-quality, nutrient-dense foods ${ }^{(46)}$.

As the present study indicates that Iraqi children below 5 years of age have a high prevalence of anaemia, a screening programme could be implemented and possible interventions might be included to improve the coverage of the distribution of fortified complementary foods, the provision of micronutrient powders, deworming and/or nutrition education (depending on the aetiology found).

Even 10 years after the 2003 invasion of Iraq, Iraqi refugees living in Lebanon continue to face hardships with implications for their food security, health and nutritional status. In light of the recent civil war in Syria and approximately 1 million Syrians who have officially registered with the UNHCR in Lebanon $^{(47)}$, the lack of interventions to address these conditions among Iraqi refugees will place a heavy burden on host nations and international organisations mandated to ensure the food security, health and well-being of refugees.

\section{Acknowledgements}

The authors thank all individuals who participated in the study, including data collectors and survey respondents. The present study was funded by the Office of the UNHCR in Beirut, Lebanon. The authors also thank Dr Andrew Seal for providing useful comments on the manuscript.

The UNHCR personnel participated in the study design and data collection; however, the UNHCR had no role in the design, analysis or writing of this article.

The views expressed in this article are those of the authors and may not be attributed to any of the following: the Economic Research Service, the US Department of Agriculture, the American University of Beirut, University of Maryland or the School of Oriental and African Studies.

The contributions of the authors are as follows: H. G. and N. R. S. conceived the study and supervised the data analysis; K. S. performed the sampling and supervised the data collection; A. J. S. contributed to the data collection; M. N. analysed the data using Rasch model assumptions; A. J. S. and H. G. drafted the manuscript. All authors were involved in the study design, data analysis and data interpretation, and approved the final version of the manuscript.

The authors declare that there are no competing interests.

\section{References}

1. United Nations High Commissioner for Refugees (2012) Syria regional refugee response: inter-agency information sharing portal. http://data.unhcr.org/syrianrefugees/regional.php (accessed 2 December 2013).

2. Margesson R, Bruno A \& Sharp JM (2009) Iraqi Refugees and Internally Displaced Persons: A Deepening Humanitarian Crisis. Washington, DC: Congressional Research Service.

3. United Nations High Commissioner for Refugees (2011) Statistical report on UNHCR registered Iraqis and non-Iraqis. 
http://www.unhcr.org/refworld/docid/4e92a86d2.html (accessed 10 October 2012).

4. United Nations High Commissioner for Refugees (2011) UNHCR Lebanon fact sheet. http://www.unhcr.org/ 4c90812e9.html (accessed 26 September 2012).

5. World Health Organization (2012) Trade, Foreign Policy, Diplomacy, and Health: Glossary of Globalization, Trade and Health Terms. Geneva: WHO. http://www.who.int/ trade/glossary/story028/en/ (accessed 10 October 2012).

6. Doocy S, Sirois A, Anderson J, et al. (2011) Food security and humanitarian assistance among displaced Iraqi populations in Jordan and Syria. Soc Sci Med 72, 273-282.

7. Black RE, Allen LH, Bhutta ZA, et al. (2008) Maternal and child undernutrition: global and regional exposures and health consequences. Lancet 371, 243-260.

8. Dixon LB, Winkleby MA \& Radimer KL (2001) Dietary intakes and serum nutrients differ between adults from food-insufficient and food-sufficient families: Third National Health and Nutrition Examination Survey, 1988-1994. J Nutr 131, 1232-1246.

9. Hackett M, Melgar-Quiñonez H \& Álvarez MC (2009) Household food insecurity associated with stunting and underweight among preschool children in Antioquia, Colombia. Rev Panam Salud Publica 25, 506-510.

10. Isanaka S, Mora-Plazas M, Lopez-Arana S, et al. (2007) Food insecurity is highly prevalent and predicts underweight but not overweight in adults and school children from Bogota, Colombia. J Nutr 137, 2747-2755.

11. Seligman HK, Bindman AB, Kanaya AM, et al. (2007) Food insecurity is associated with diabetes mellitus: results from the National Health Examination and Nutrition Examination Survey (NHANES) 1999-2002. J Gen Intern Med 22, 1018-1023.

12. Seligman HK, Laraia BA \& Kushel MB (2010) Food insecurity is associated with chronic disease among low-income NHANES participants. J Nutr 140, 304-310.

13. World Health Organization (2004) Macroeconomics and Health. Geneva: WHO. http://www.who.int/macrohealth/ en/ (accessed 10 April 2012).

14. Chaaban JM, Seyfert K, Salti NI, et al. (2013) Poverty and livelihoods among UNHCR registered refugees in Lebanon. Refugee Survey Quarterly 32, 24-49.

15. The World Bank (2007) Iraq Household Socio-Economic Survey - IHSES. http://go.worldbank.org/GMS95L4VH0 (accessed 10 October 2012).

16. Nord M, Andrews M \& Carlson S (2009) Household Food Security in the United States 2008. Washington, DC: USDA.

17. Bickel G, Nord M, Price C, et al. (2000) Guide to Measuring Household Food Security. Alexandria, VA: U.S. Department of Agriculture.

18. Kabbani N \& Wehelie Y (2004) Measuring hunger and food insecurity in Yemen. In Eleventh Annual Conference of the Economic Research Forum, 14-16 December 2004, Beirut, Lebanon.

19. Maxwell D, Watkins B, Wheeler R, et al. (2003) Coping Strategies Index a Tool for Rapidly Measuring Food Security and the Impact of Food Aid Programmes in Emergencies: Field Methods Manual. Nairobi: CARE and WFP.

20. Food and Agriculture Organization (2011) Guidelines for Measuring Housebold and Individual Dietary Diversity. Rome: FAO.

21. Swindale A \& Bilinsky P (2006) Household Dietary Diversity Dcore (HDDS) for Measurement of Housebold Food Access: Indicator Guide (Version 2). Washington, DC: USAID and AED.
22. World Health Organization (2011) Haemoglobin Concentrations for the Diagnosis of Anaemia and Assessment of Severity. Geneva: WHO. http://www.who.int/vmnis/indicators/ haemoglobin.pdf (accessed 1 December 2012).

23. United Nations High Commissioner for Refugees (2012) UNHCR statistical online population database. http://apps. who.int/globalatlas/default.asp (accessed 25 October 2012).

24. Ghattas H, Seyfert K \& Sahyoun NR (2012) Food insecurity among Palestinian refugees living in Lebanon: a household survey. Lancet 380, S7-S8.

25. Siefert K, Heflin CM, Corcoran ME, et al. (2001) Food insufficiency and the physical and mental health of low-income women. Women Health 32, 159-177.

26. Casey P, Goolsby S, Berkowitz C, et al. (2004) Maternal depression, changing public assistance, food security, and child health status. Pediatrics 113, 298-304.

27. Stuff JE, Casey PH, Szeto KL, et al. (2004) Household food insecurity is associated with adult health status. J Nutr $\mathbf{1 3 4}$, 2330-2335.

28. Laraia BA, Siega-Riz AM, Gundersen C, et al. (2006) Psychosocial factors and socioeconomic indicators are associated with household food insecurity among pregnant women. J Nutr 136, 177-182.

29. Peterman JN, Wilde PE, Silka L, et al. (2012) Food insecurity among Cambodian refugee women two decades post resettlement. J Immigr Minor Health 15, 372-380.

30. Melchior M, Chastang J-F, Falissard B, et al. (2012) Food insecurity and children's mental health: a prospective birth cohort study. PLOS ONE 7, e52615.

31. Rose D (1999) Economic determinants and dietary consequences of food insecurity in the United States. J Nutr 129, 517S-520S.

32. Sen A (1979) Issues in the measurement of poverty. Scand J Econ 81, 285-307.

33. Sen A (1993) Capability and well-being. In The Quality of Life, pp. 30-53 [M Nussbaum and A Sen, editors]. Oxford: Clarendon Press.

34. Beverly SG (2001) Measures of material hardship. J Poverty 5 , 23-41.

35. Quandt SA, Arcury TA, Early J, et al. (2004) Household food security among migrant and seasonal Latino farmworkers in North Carolina. Public Health Rep 119, 568-576.

36. Weigel MM, Armijos RX, Hall YP, et al. (2007) The household food insecurity and health outcomes of U.S.-Mexico border migrant and seasonal farmworkers. J Immigr Minor Health $\mathbf{9}$, 157-169.

37. Shariff ZM \& Khor GL (2008) Household food insecurity and coping strategies in a poor rural community in Malaysia. Nutr Res Pract 2, 26-34.

38. De Marco M, Thorburn S \& Kue J (2009) In a country as affluent as America, people should be eating: experiences with and perceptions of food insecurity among rural and urban Oregonians. Qual Health Res 19, 1010-1024.

39. Hoddinott J \& Yohannes Y (2002) Dietary Diversity as a Food Security Indicator. Washington, DC: International Food Policy Research Institute.

40. Azadbakht L \& Esmaillzadeh A (2011) Dietary diversity score is related to obesity and abdominal adiposity among Iranian female youth. Public Health Nutr 14, 62-69.

41. Allen LH (2006) Causes of nutrition-related public health problems of preschool children: available diet. $J$ Pediatr Gastoenterol Nutr 43, S8-S12.

42. Centers for Disease Control and Prevention (2010) Health of resettled Iraqi refugees in San Diego County, California, 
October 2007-September 2009. MMWR Morb Mortal Wkly Rep 59, 1614-1618.

43. United Nations Children's Fund (2010) Nutrition Profile: Lebanon. New York: United Nations Children's Emergency Fund (UNICEF). http://www.childinfo.org/files/nutrition/ DI\%20Profile\%20-\%20Lebanon.pdf (accessed 15 November 2012).

44. Grijalva-Eternod CS, Wells JC, Cortina-Borja M, et al. (2012) The double burden of obesity and malnutrition in a protracted emergency setting: a cross-sectional study of Western Sahara refugees. PLoS Med 9, e1001320.
45. Herman DR, Harrison GG \& Jenks E (2006) Choices made by low-income women provided with an economic supplement for fresh fruit and vegetable purchase. J Am Diet Assoc 106, 740-744.

46. Kirks BA, Hendricks DG \& Wyse BW (1982) Parent involvement in nutrition education for primary grade students. J Nutr Educ 14, 137-140.

47. United Nations High Commissioner for Refugees (2012) Syria regional refugee response. Information sharing portal. http://data.unhcr.org/syrianrefugees/regional.php (accessed 4 November 2012). 